\title{
Boron-Doped Carbon Nano-/Microballs from Orthoboric Acid-Starch: Preparation, Characterization, and Lithium Ion Storage Properties
}

\author{
Xinhua Lu $\mathbb{D}$ and Lin Chen \\ Nanjing Polytechnic Institute, Nanjing 210048, China \\ Correspondence should be addressed to Xinhua Lu; 13912905687@126.com and Lin Chen; 751016176@qq.com
}

Received 13 October 2017; Accepted 25 February 2018; Published 23 April 2018

Academic Editor: Zafar Iqbal

Copyright (C) 2018 Xinhua Lu and Lin Chen. This is an open access article distributed under the Creative Commons Attribution License, which permits unrestricted use, distribution, and reproduction in any medium, provided the original work is properly cited.

\begin{abstract}
A boron-doped carbon nano-/microballs (BC) was successfully obtained via a two-step procedure including hydrothermal reaction $\left(180^{\circ} \mathrm{C}\right)$ and carbonization $\left(800^{\circ} \mathrm{C}\right)$ with cheap starch and $\mathrm{H}_{3} \mathrm{BO}_{3}$ as the carbon and boron source. As a new kind of boron-doped carbon, $\mathrm{BC}$ contained 2.03 at $\%$ B-content and presented the morphology as almost perfect nano-/microballs with different sizes ranging from $500 \mathrm{~nm}$ to $5 \mu \mathrm{m}$. Besides that, due to the electron deficient boron, $\mathrm{BC}$ was explored as anode material and presented good lithium storage performance. At a current density of $0.2 \mathrm{C}$, the first reversible specific discharge capacity of $\mathrm{BC}$ electrode reached as high as $964.2 \mathrm{mAh} \mathrm{g}^{-1}$ and kept at $699 \mathrm{mAh} \mathrm{g}^{-1}$ till the 11th cycle. BC also exhibited good cycle ability with a specific capacity of $356 \mathrm{mAh} \mathrm{g}^{-1}$ after 79 cycles at a current density of $0.5 \mathrm{C}$. This work proved to be an effective approach for boron-doped carbon nanostructures which has potential usage for lithium storage material.
\end{abstract}

\section{Introduction}

To date, several approaches including enriching the morphology of solid-liquid interface [1-3] and increasing the lithium intercalation sites embedded with versatile heteroatoms have attracted great attention to improve the electrochemical performance of carbonaceous anodic materials [4-8]. Among them, nanostructured morphologies [9-14] and heteroatoms embedment have been disclosed to be two of the most important approaches for carbonaceous anodes with brilliant, interesting, and enhanced physicochemical and electrochemical properties.

Various precursors with different heteroelement species [15-18] or increased amount of heteroatoms [4, 9, 10, 19-22] including $\mathrm{N}[20,23-25], \mathrm{P}[4,15-18,26-30], \mathrm{S}$ [31-34], Si $[9,21,22]$, and Sn-doping $[7,35,36]$ have been explored to upgrade the carbonaceous anodic materials for $\mathrm{Li}^{+}$ion storage due to their great high theoretical specific capacity of $\mathrm{Li}^{+}$ion storage. Although boron could effectively adjust the lattice defect related to the structure disorder of carbon materials, there are quite few reports on boron-doped carbon as $\mathrm{Li}^{+}$ion storage anode [37]. Previous reported boron-doped carbons were investigated as the cathode catalysts for $\mathrm{Na}$ O batteries [38], carbon paste electrode [39], supercapacitor [40-43], and $\mathrm{H}_{2}$ physisorption [44] with improved versatile characteristics including oxidation activity and electrochemical performance. One important reason for the lack research of boron-doped carbon is ascribed to the less of boron sources except for the reported $\mathrm{BF}_{3}[45,46], \mathrm{HBO}_{3}[38,40]$, and $\mathrm{BCl}_{3}$ [47]. Another reason was the low doping ratio with few reports surpassing over 2 at\% (4.8-9.6 at\% [40], 5.57 at\% [45], and 7 at\% [44]) most likely due to the difficulty to form homogeneously dispersed boron and unstable C-B bond tending to be hydrolysis [45]. In this case, it is emergent and necessary to develop a kind of facile synthesis and high yield boron-doped carbon for high performed carbonaceous anodic lithium storage materials.

In this contribution, we have successfully achieved one new boron-doped carbon (BC) by a two-step procedure (Scheme 1) including hydrothermal reaction at $180^{\circ} \mathrm{C}$ and carbonization at $800^{\circ} \mathrm{C}$ under Ar atmosphere with commercial available starch and orthoboric acid $\left(\mathrm{H}_{3} \mathrm{BO}_{3}\right)$ and active agent as the carbon and boron sources. $\mathrm{BC}$ was characterized by X-ray photoelectron spectroscopy (XPS), X-ray powder 


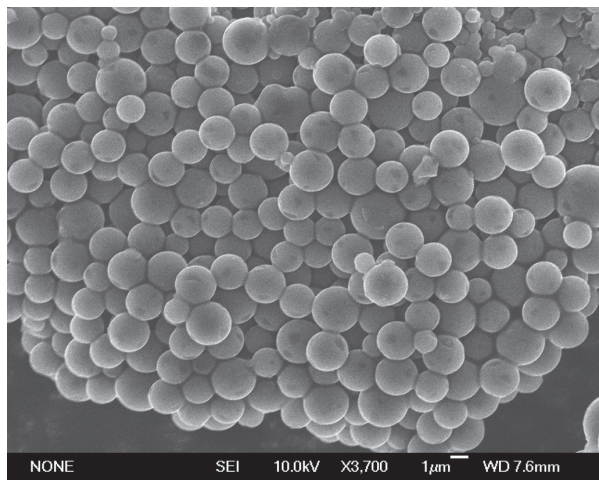

(a)

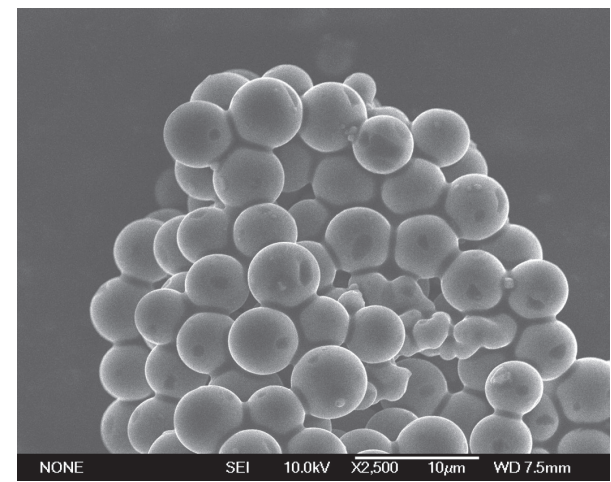

(b)

FIGURE 1: FE-SEM images of BC with different magnificence.

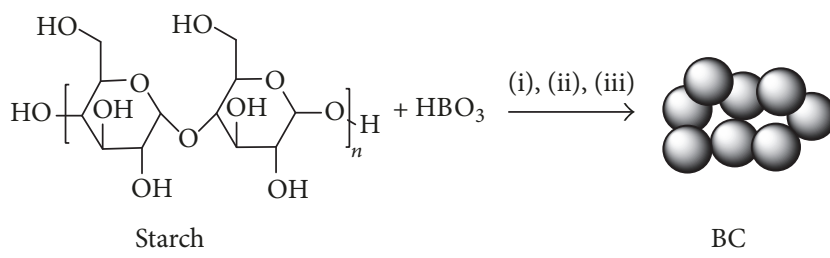

SCHEME 1: Preparation procedure of boron-doped carbon nano-/ microballs: (i) hydrothermal reaction, $180^{\circ} \mathrm{C}$, washing with deionized water; (ii) pyrolysis, $\mathrm{Ar}, 800^{\circ} \mathrm{C}, 2 \mathrm{~h}$; (iii) activation, $\mathrm{ZnCl}_{2}, \mathrm{Ar}$, $800^{\circ} \mathrm{C}, 2 \mathrm{~h}$, washing with $\mathrm{HCl}$ (aq.), deionized water.

diffraction (XRD), Raman spectrum, field emission scanning electron microscope (FE-SEM), electrochemical tests including cyclic voltammetry $(\mathrm{CV})$, electrochemical impedance spectroscopy (EIS) with cycle stability and columbic efficiency, and rate performance of $\mathrm{Li}^{+}$ion battery.

\section{Results and Discussion}

2.1. Synthesis. The boron-doped carbon was synthesized via a two-step procedure [48-50]. The most important procedure was the first step, of which the high temperature, high pressure, and ionic water got three purposes: (a) to promote the swelling and reshaping of microcrystal bundle of starch with deionized water; (b) to improve the penetration and absorbance of $\mathrm{HBO}_{3}$ into the microcrystal bundle of starch; (c) to speed up the bonding of $\mathrm{HBO}_{3}$ with -OH groups of starch. It has been reported that the morphology of starch powder tended to be nano-/microspheres $[49,50]$ with sizes in a certain range. A black powder was finally obtained as boron-doped carbon (BC) representing a successful carbonation procedure in the second step.

2.2. Morphology. To find out the detailed morphology of BC, FE-SEM was applied. Figure 1(a) presented with structures as imperfect round nano-/microballs spreading in the range of $500 \mathrm{~nm}-5 \mu \mathrm{m}$ with magnificent picture as shown in Figure $1(\mathrm{~b})$. The low intensity meant the weak graphitization for BC. Calculated with Bragg's Law $2 d \sin \theta=n \lambda(\lambda=$ $1.5405 \AA), d 002$ peak was $0.40 \mathrm{~nm}\left(22.3^{\circ}\right)$ and $2.08 \mathrm{~nm}\left(43.3^{\circ}\right)$ both wider compared to the smallest graphitic spacing (d002) $0.34 \mathrm{~nm}$ [51] and $0.21 \mathrm{~nm}$ [52], hinting the more crystalline defects of this new boron-doped carbon compared to graphite.

2.3. Raman Spectrum. As depicted in Figure 2(b), the Raman spectrum exhibited two distinct peaks at $\mathrm{D}$ banded $c a$. $1336 \mathrm{~cm}^{-1}$ and G banded $c a .1588 \mathrm{~cm}^{-1}$ representing graphitic and disordered $\mathrm{sp}^{2}$-carbon atoms of BC. The more intensive G bands marked the typical graphitic lattice vibration [53, 54]. The less intensive $D$ bands represented the defect lattice vibration $[55,56]$. The intensity ratio of $\mathrm{D}$-band versus $\mathrm{G}$ band $\left(I_{\mathrm{D}} / I_{\mathrm{G}}\right)$ value was calculated to be 0.985 indicating the structural and intrinsic defects and amorphous disorder [5760] for BC.

2.4. X-Ray Photoelectron Spectroscopy (XPS). XPS was measured to analyze the elemental species and their corresponding atom percentage in the obtained boron-doped carbon. As presented in Figure 3(a), BC mainly contained C, B, and $\mathrm{O}$ dopants with three characteristic peaks at $\sim 284 \mathrm{eV}$, $\sim 192 \mathrm{eV}$, and $\sim 532 \mathrm{eV}$ corresponding to $\mathrm{C} 1 \mathrm{~s}, \mathrm{~B} 1 \mathrm{~s}$, and $\mathrm{O}$ 1s, respectively. For BC, the total contents of $\mathrm{C}, \mathrm{B}$, and $\mathrm{O}$ elements were 84.06 at $\%, 2.03$ at $\%$, and 13.91 at $\%$, respectively.

In Figure 3(b), the $\mathrm{C}$ 1s spectrum of the $\mathrm{BC}$ could be deconvoluted into several individual peaks. The top peak at ca. $284.4 \mathrm{eV}$ was most likely ascribed to the $\mathrm{sp}^{2}-\mathrm{C}$ of $\mathrm{C}=\mathrm{C}$ double bonds $[15-18,27]$. However, the $\mathrm{C}$ 1s of B-C-X could not be observed due to the low percentage. According to the fact of boron-doping ratio, the second peak at $285.5 \mathrm{eV}$ was partially ascribed to the C-B bond which was buried in the second peak with other bond species. Partial of the second peak and the last one was defined as the signal of $\mathrm{C}-\mathrm{O} / \mathrm{C}=\mathrm{O}$ bonds $[16,17]$. These $\mathrm{C}$ of $\mathrm{BC}$ took corresponding ratio as 56.94 at $\%, 21.29$ at\%, and 5.2 at\%, respectively. In Figure 3(c), after analyzing the high resolution spectra of BC sample in the range of $180-196 \mathrm{eV}$. The high resolution B 1s peak at $191.6 \mathrm{eV}$ was evidence for the existence of B species $[39,46]$. The splitted two peaks at $191.2 \mathrm{eV}$ and $192.6 \mathrm{eV}$ took 0.58 at\% and 1.55 at $\%$, respectively, belonging to $\mathrm{B} 1 \mathrm{~s}$ of $\mathrm{B}-\mathrm{C}_{3}, \mathrm{~B}-\mathrm{C}_{2} \mathrm{O}$ with different bonding species [18]. In Figure 3(d), the $\mathrm{O}$ 1s 


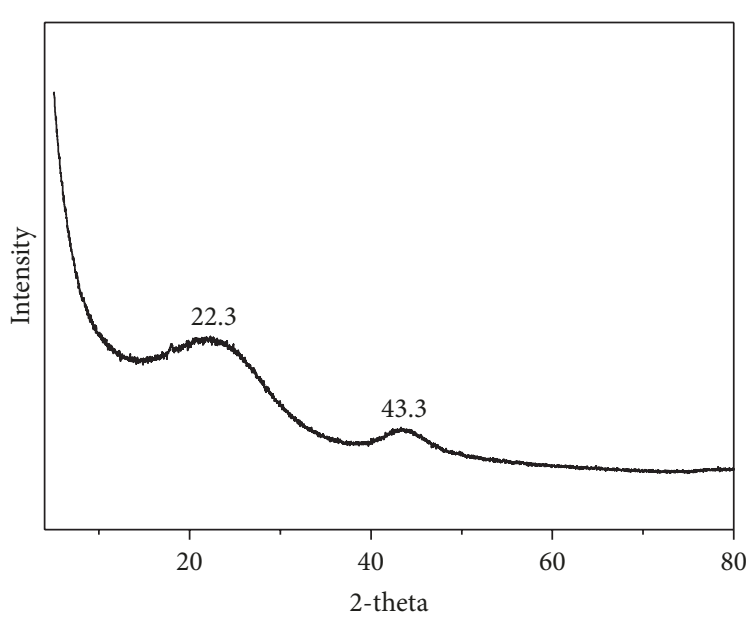

(a)

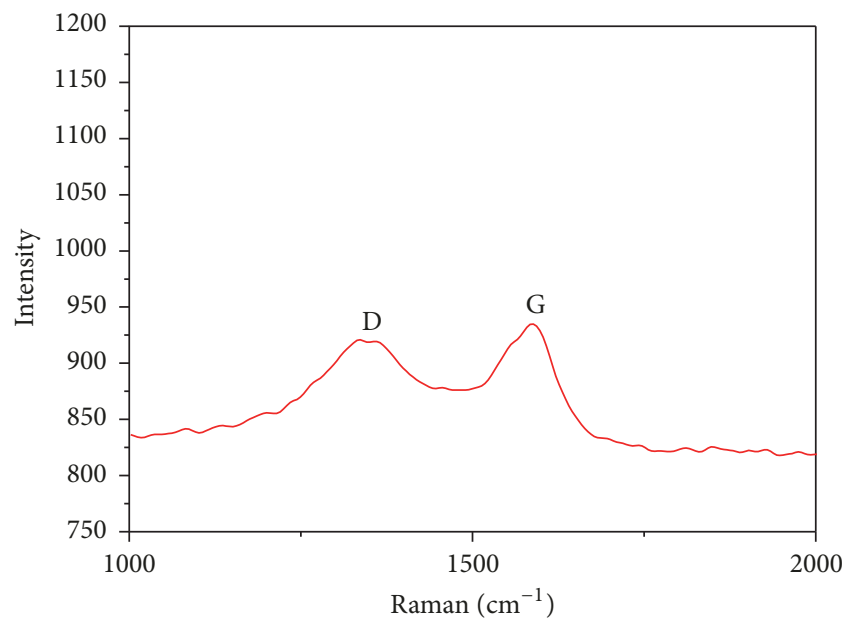

$-\mathrm{BC}$

(b)

FIGURE 2: (a) XRD pattern of BC; (b) the Raman spectra of BC.
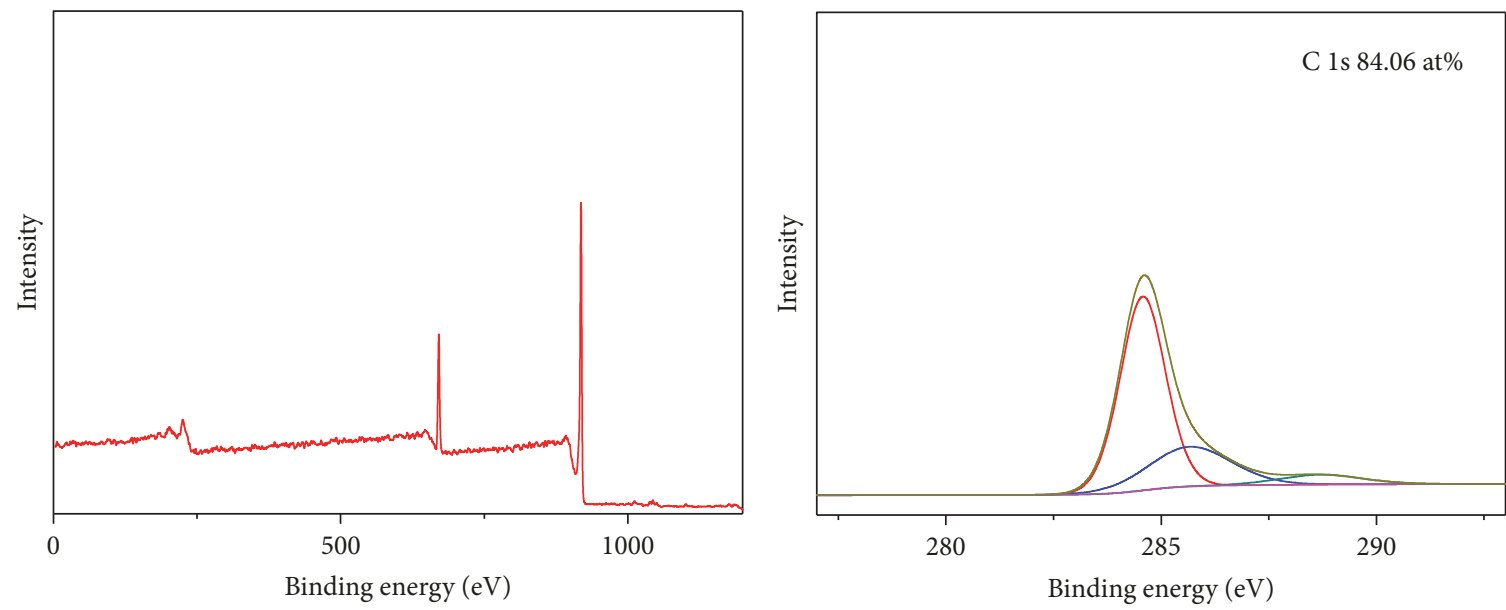

(a)

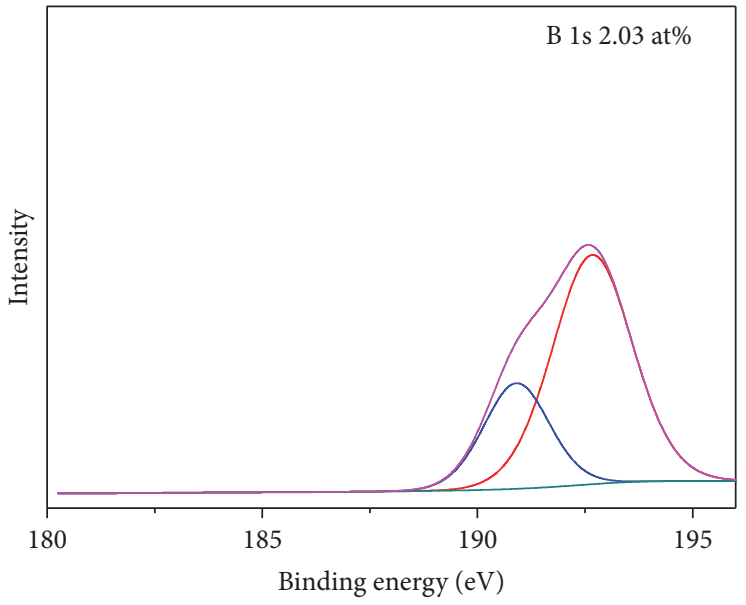

(c) (b)

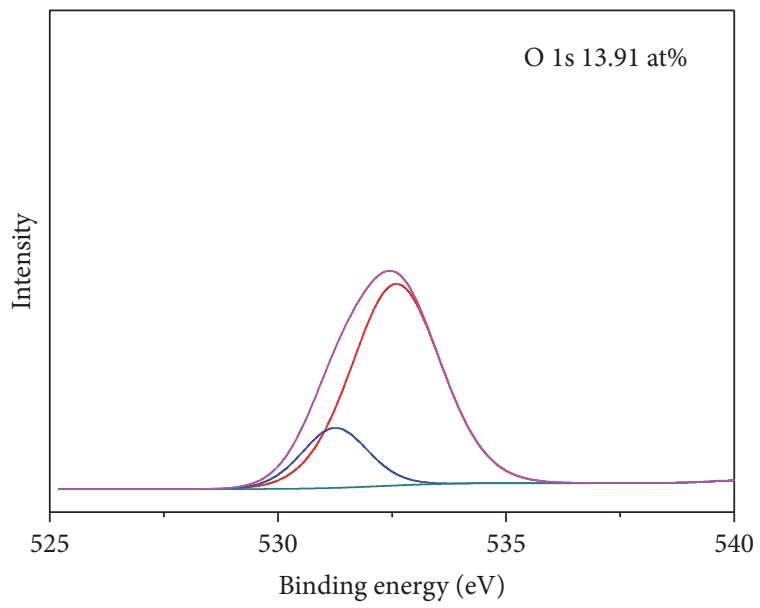

(d)

Figure 3: The C 1s (c), B 1s (c), and O 1s (d) XPS spectrum of splitted curves of BC. 


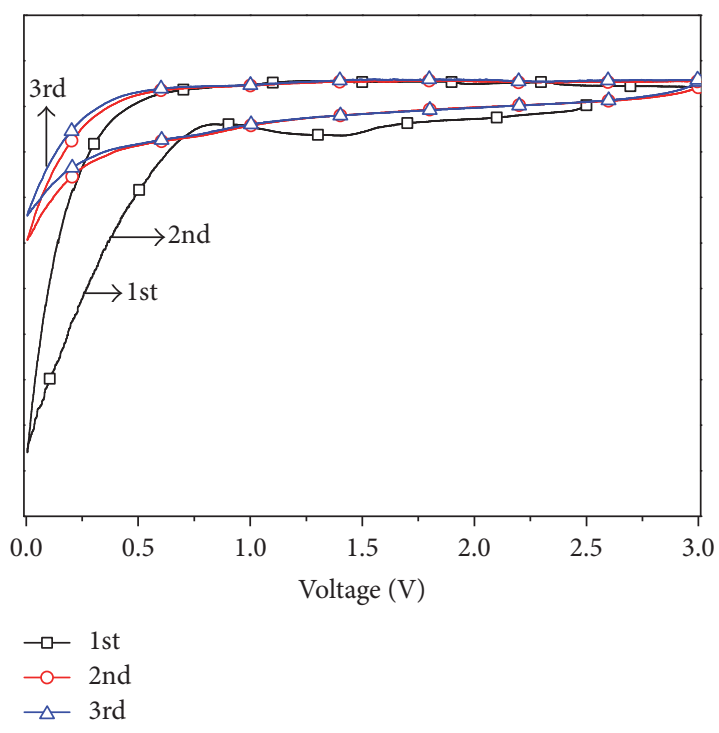

(a)

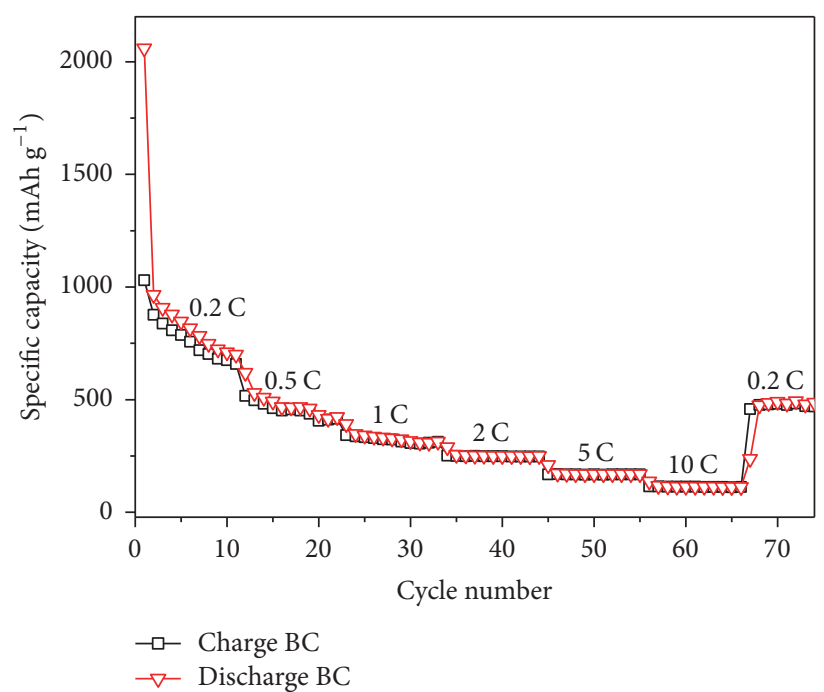

(b)

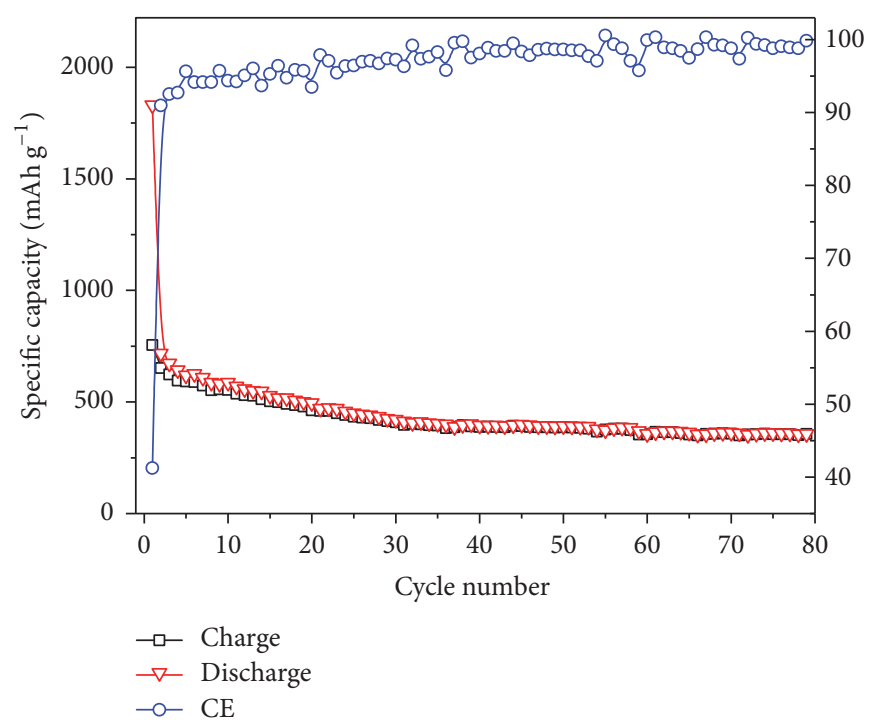

(c)

FIGURE 4: (a) Cyclic voltammograms at a scan rate of $0.5 \mathrm{mV} \mathrm{s}^{-1}$ of $\mathrm{BC}$; (b) rate performance at different current densities from $0.2-10 \mathrm{C}$ of $\mathrm{BC}$; (c) cycleability and Columbic efficiency at $0.5 \mathrm{C}$ of BC.

spectrum of BC was also detected and divided to be two peaks at $531.9 \mathrm{eV}$ and $533.6 \mathrm{eV}$ covering 2.60 at\% and $11.84 \mathrm{at} \%$ and matched with the $\mathrm{O} 1 \mathrm{~s}$ from $\mathrm{O}=\mathrm{C}$ double bond and $\mathrm{O}-\mathrm{C}$ single bond, respectively. Neither for $\mathrm{O}$ 1s was observed from $\mathrm{B}-\mathrm{O}$ bond due to the low percentage.

2.5. Electrochemical Performance. Figure 4(a) presents the first three voltage curves of BC electrode measured by cyclic voltammogram $(\mathrm{CV})$ at room temperature from $0.005 \mathrm{~V}$ to $3.0 \mathrm{~V}$ with a $0.5 \mathrm{mV} \mathrm{s}^{-1}$ scan speed. The discharge curve of $1 \mathrm{st}$ cycle has not covered the 2 nd and 3 rd. The initial obvious sharp peaks at $0.01-0.7 \mathrm{~V}$ were most likely induced by the solid electrolyte interphase (SEI) layer [61-65]. Figure 4(b) represented the rate cycle curve at several increased current densities from $0.2 \mathrm{C}, 0.5 \mathrm{C}, 1 \mathrm{C}, 2 \mathrm{C}$, and 5 to $10 \mathrm{C}$. At $0.2 \mathrm{C}$, there was a great decrease from the initial irreversible discharge capacity (2059 $\left.\mathrm{mAh} \mathrm{g}^{-1}\right)$ to the initial reversible charge capacity $\left(1030 \mathrm{mAh} \mathrm{g}^{-1}\right)$ which was most likely induced by the SEI reaction. However, at the 1st reversible cycle, the specific discharge capacity of BC electrode reached as high as $964 \mathrm{mAh} \mathrm{g}^{-1}$ and stabilized at $699 \mathrm{mAh} \mathrm{g}^{-1}$ by the end of the 11th cycle which were nearly two times higher than the theoretical top value of graphite electrode $\left(372 \mathrm{mAh} \mathrm{g}^{-1}\right)$ with the $\mathrm{LiC}_{6}$ mechanism [63-65]. At the highest current density of $10 \mathrm{C}$, the capacity kept at $\sim 116.8 \mathrm{mAh} \mathrm{g}^{-1}$ till the 57 th cycle [66-70]. When the current density was adjusted back to $0.2 \mathrm{C}$ at the 70th cycle, the discharge capacity recovered to $490 \mathrm{mAh} \mathrm{g}^{-1}$ for BC electrode.

Figure 4(c) shows the cycleability and columbic efficiency at a current density of $0.2 \mathrm{C}$ of $\mathrm{BC}$ electrode. The $\mathrm{BC}$ 


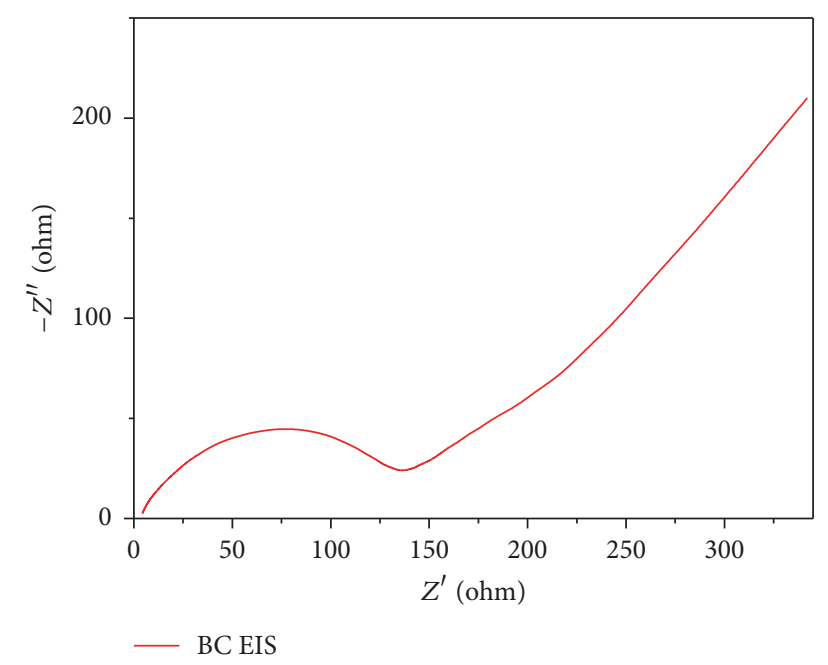

FIGURE 5: Electrochemical impedance spectroscopy of BC electrode.

electrode possessed stable cycle stability with the corresponding capacity as high as $356 \mathrm{mAh} \mathrm{g}^{-1}$ after 79 cycles at $0.5 \mathrm{C}$. The 1st irreversible discharge capacity of $\mathrm{BC}$ reached $1829 \mathrm{mAh} \mathrm{g}^{-1}$. Beginning with the $37 \mathrm{th}$ cycle, the discharge capacity stabilized between 386 and $357 \mathrm{mAh} \mathrm{g}^{-1}$ till the 79th cycle. However, the columbic efficiencies are almost over $90 \%$ from the 2 nd cycle to the 79 th cycle.

As presented in Figure 5, The nano-/microstructures of $\mathrm{BC}$ particles determined the charge-transfer process of lithium ion insertion/extraction reaction [67, 68]. According the reported literature, the calculated value as $138 \Omega$ for BC electrode was regarded as a composite resistance value determining the charge transfer of $\mathrm{Li}^{+}$ions insertion/extraction $[69,70]$. The composite resistance value contained the $\mathrm{Li}^{+}$ ions migration through the SEI film and charge-transfer resistance. As illustrated above, the carbonaceous body of $\mathrm{BC}$ played a role as the conductive channels [20, 23, 71] for electron transportation. The enlarged electrode/electrolyte interface of BC could promote the rapid absorption and release of $\mathrm{Li}^{+}$ions with fast charge-transfer process. Meanwhile, the transport distances of $\mathrm{Li}^{+}$ions were shortened on the carbon framework.

\section{Conclusions}

In summary, a novel boron-doped carbon has been obtained by a two-step approach hydrothermal reaction and carbonization treatment and explored as anode materials for $\mathrm{Li}^{+}$ion battery. The ratio of boron-doping reached as high as 2.03 at\%. The morphology presented as perfect nano-/microballs ranging from $500 \mathrm{~nm}$ to $5 \mu \mathrm{m}$. At a current density of $0.5 \mathrm{C}, \mathrm{BC}$ electrode exhibited good cycle ability with a discharge capacity of $356 \mathrm{mAhg}^{-1}$ till 79 cycles. We gave a facile approach to reach a boron-doped carbon. Further investigation to much higher ratio of borondoping is undergoing for more highly performed $\mathrm{Li}^{+}$ion battery.

\section{Experimental Section}

4.1. Materials. Potato starch was purchased from supermarket and $\mathrm{H}_{3} \mathrm{BO}_{3}$, and $\mathrm{ZnCl}_{2}$ [72-74] were purchased from Sigma-Aldrich Co., Ltd. Other reagents and solvents were purchased from Energy Co., Ltd. All solvents were used without further purification.

4.2. Synthesis of BC Nano-/Microballs. There were mainly two steps for the synthetic routine. In the first step, the mixture of $\mathrm{HBO}_{3}$, starch and deionized water was treated with hydrothermal reaction under a high temperature circumstance at $180^{\circ} \mathrm{C}$. In the second step, the starch particles loaded with $\mathrm{HBO}_{3}$ were grinded with overdose $\mathrm{ZnCl}_{2}$ to isolate the starch particles and avoid the conglutination and then carbonized at $800^{\circ} \mathrm{C}$ for $2 \mathrm{~h}$ under Ar atmosphere. The detailed procedure was carried out as $10 \mathrm{~g}$ potato starch, $7.14 \mathrm{~g}$ $\mathrm{H}_{3} \mathrm{BO}_{3}$, and $180 \mathrm{ml}$ deionized water was added to hydrothermal reactor and heated at $180^{\circ} \mathrm{C}$ for $24 \mathrm{~h}$. After cooling to room temperature, brown yellow powder was obtained by vacuum filtration, washed by deionized water, and dried at vacuum oven at $120^{\circ} \mathrm{C}$ overnight. The powder was grinded with $\mathrm{ZnCl}_{2}$ (1:4, weight ratio) for $15 \mathrm{~min}$ and divided to be three parts which were calcined at $800^{\circ} \mathrm{C}$ for $2 \mathrm{~h}$ with a heat ascending rate of $5^{\circ} \mathrm{C} \mathrm{min}^{-1}$, respectively. The obtained three kinds of black powder were washed by $\mathrm{HCl}\left(6 \mathrm{~mol} \mathrm{~L}^{-1}\right)$ and deionized water till $\mathrm{pH}=7.0$ giving target boron-doped carbon materials entitled BC. The particles were scanned by FE-SEM and confirmed to be nano-/microballs.

4.3. Methods. Field emission scanning electron microscopy (Hitachi S-4800, Tokyo, Japan) was used to observe the micromorphology of particles. Bruker D8 X-ray diffractometer with $\mathrm{Cu} \mathrm{K} \alpha$ Radiation $(\lambda=1.5405 \AA)$ was used to measure the X-ray diffraction (XRD) patterns of aggregate sample. WITec alpha 300M+ micro-Raman confocal microscopy was used to test collect the Raman spectra of as-prepared sample. Thermo Scientific ESCALAB 250XI system with a monochromatic $\mathrm{Al} \mathrm{K} \alpha \mathrm{X}$-ray source was used to carry out the XPS measurements of elemental data.

4.4. Electrochemical Tests. The electrochemistry property of BC was tested with button cells. Pure lithium was used as the counterelectrode and reference electrode. The working electrodes were fabricated by mixing the mixture of BC and polyvinylidene fluoride (PVDF) (90 wt\%:10 wt\%) in $N$-methyl-2-pyrrolidone (NMP). The obtained mixture was coated onto $\mathrm{Al}$ sheet and dried for $12 \mathrm{~h}$ in a vacuum oven. The electrolyte was a $1.0 \mathrm{~mol} \mathrm{~L}^{-1} \mathrm{LiPF}_{6}$ in $\mathrm{Et}_{2} \mathrm{CO}_{3} / \mathrm{Me}_{2} \mathrm{CO}_{3}$. The electrodes were assembled into button cells in an Arfilled glove box (moisture/oxygen $<0.1 \mathrm{ppm}$ ). The galvanostatic tests of the button cells were measured with a NEWARE battery-testing system. The alternative current (AC) impedance was carried out on a CHI 760D electrochemical workstation (CH Instruments, Inc.).

\section{Conflicts of Interest}

The authors declare that they have no conflicts of interest. 


\section{References}

[1] L. Bhattacharjee, R. Manoharan, K. Mohanta, and R. R. Bhattacharjee, "Conducting carbon quantum dots-a nascent nanomaterial," Journal of Materials Chemistry A, vol. 3, no. 4, pp. 1580-1586, 2015.

[2] G. Chen, L. Yan, H. Luo, and S. Guo, "Nanoscale Engineering of Heterostructured Anode Materials for Boosting Lithium-Ion Storage," Advanced Materials, vol. 28, no. 35, pp. 7580-7602, 2016.

[3] C. Chen, D. Yu, G. Zhao et al., "Three-dimensional scaffolding framework of porous carbon nanosheets derived from plant wastes for high-performance supercapacitors," Nano Energy, vol. 27, pp. 377-389, 2016.

[4] C. Zhang, N. Mahmood, H. Yin, F. Liu, and Y. Hou, "Synthesis of phosphorus-doped graphene and its multifunctional applications for oxygen reduction reaction and lithium ion batteries," Advanced Materials, vol. 25, no. 35, pp. 4932-4937, 2013.

[5] W. Ai, J. Jiang, J. Zhu et al., "Toward high energy organic cathodes for li-ion batteries: a case study of vat dye/graphene composites," Advanced Energy Materials, vol. 5, Article ID 1500559, 2015.

[6] L. Chuenchom, R. Kraehnert, and B. M. Smarsly, "Recent progress in soft-templating of porous carbon materials," Soft Matter, vol. 8, no. 42, pp. 10801-10812, 2012.

[7] S. Dutta, A. Bhaumik, and K. C.-W. Wu, "Hierarchically porous carbon derived from polymers and biomass: Effect of interconnected pores on energy applications," Energy \& Environmental Science, vol. 7, no. 11, pp. 3574-3592, 2014.

[8] H. Song, N. Li, H. Cui, and C. Wang, "Enhanced storage capability and kinetic processes by pores- and hetero-atomsriched carbon nanobubbles for lithium-ion and sodium-ion batteries anodes," Nano Energy, vol. 4, pp. 81-87, 2014.

[9] J. H. Park, L. Gu, G. von Maltzahn, E. Ruoslahti, S. N. Bhatia, and M. J. Sailor, "Biodegradable luminescent porous silicon nanoparticles for in vivo applications," Nature Materials, vol. 8, no. 4, pp. 331-336, 2009.

[10] H. Chen, Y. Wei, J. Wang, W. Qiao, L. Ling, and D. Long, "Controllable Nitrogen Doping of High-Surface-Area Microporous Carbons Synthesized from an Organic-Inorganic SolGel Approach for Li-S Cathodes," ACS Applied Materials \& Interfaces, vol. 7, no. 38, pp. 21188-21197, 2015.

[11] K. Ariga, A. Vinu, Y. Yamauchi, Q. Ji, and J. P. Hill, "Nanoarchitectonics for mesoporous materials," Bulletin of the Chemical Society of Japan, vol. 85, no. 1, pp. 1-32, 2012.

[12] Y. Zhai, Y. Dou, D. Zhao, P. F. Fulvio, R. T. Mayes, and S. Dai, "Carbon materials for chemical capacitive energy storage," Advanced Materials, vol. 23, no. 42, pp. 4828-4850, 2011.

[13] Y. Chen, X. Li, K. Park et al., "Hollow carbon-nanotube/carbonnanofiber hybrid anodes for Li-ion batteries," Journal of the American Chemical Society, vol. 135, no. 44, pp. 16280-16283, 2013.

[14] J. Yang, J. Xie, X. Zhou et al., "Functionalized n-doped porous carbon nanofiber webs for a lithium-sulfur battery with high capacity and rate performance," The Journal of Physical Chemistry C, vol. 118, no. 4, pp. 1800-1807, 2014.

[15] J. P. Paraknowitsch and A. Thomas, "Doping carbons beyond nitrogen: An overview of advanced heteroatom doped carbons with boron, sulphur and phosphorus for energy applications," Energy \& Environmental Science, vol. 6, no. 10, pp. 2839-2855, 2013.
[16] M. Xing, F. Shen, B. Qiu, J. Zhang, and Sci., "Highly-dispersed boron-doped graphene nanosheets loaded with $\mathrm{TiO} 2$ nanoparticles for enhancing CO2 photoreduction," Science Reports, vol. 4, p. 6341, 2014.

[17] A. Kalijadis, J. DorCevidć, T. Trtić-Petrović et al., "Preparation of boron-doped hydrothermal carbon from glucose for carbon paste electrode," Carbon, vol. 95, pp. 42-50, 2015.

[18] Y. Lin, Y. Zhu, B. Zhang, Y. A. Kim, M. Endo, and D. S. Su, "Boron-doped onion-like carbon with enriched substitutional boron: The relationship between electronic properties and catalytic performance," Journal of Materials Chemistry A, vol. 3, no. 43, pp. 21805-21814, 2015.

[19] S. Wang, L. Zhang, Z. Xia et al., "BCN graphene as efficient metal-free electrocatalyst for the oxygen reduction reaction," Angewandte Chemie International Edition, vol. 51, no. 17, pp. 4209-4212, 2012.

[20] A. S. Yatsenko, A. K. Marrone, and H. R. Shcherbata, "High lithium anodic performance of highly nitrogen-doped porous carbon prepared from a metal-organic framework," Nature Communications, vol. 5, 5261, 2014.

[21] Y. Shen, P. Zhao, and Q. Shao, "Porous silica and carbon derived materials from rice husk pyrolysis char," Microporous and Mesoporous Materials, vol. 188, pp. 46-76, 2014.

[22] J. M. Pan, J. F. Pan, X. N. Cheng et al., "Synthesis of hierarchical porous silicon oxycarbide ceramics from preceramic polymer and wood biomass composites," Journal of the European Ceramic Society, vol. 34, pp. 249-256, 2014.

[23] L. Qie, W.-M. Chen, Z.-H. Wang et al., "Nitrogen-doped porous carbon nanofiber webs as anodes for lithium ion batteries with a superhigh capacity and rate capability," Advanced Materials, vol. 24, no. 15, pp. 2047-2050, 2012.

[24] C. Hu, Y. Xiao, Y. Zhao et al., "Highly nitrogen-doped carbon capsules: Scalable preparation and high-performance applications in fuel cells and lithium ion batteries," Nanoscale, vol. 5, no. 7, pp. 2726-2733, 2013.

[25] H. Wang, M. Xie, L. Thia, A. Fisher, and X. Wang, "Strategies on the design of nitrogen-doped graphene," The Journal of Physical Chemistry Letters, vol. 5, no. 1, pp. 119-125, 2014.

[26] J. Yi, Y. Qing, C. Wu et al., "Lignocellulose-derived porous phosphorus-doped carbon as advanced electrode for supercapacitors," Journal of Power Sources, vol. 351, pp. 130-137, 2017.

[27] W. Ai, X. Wang, C. Zou et al., "Boric acid-mediated B,Ncodoped chitosan-derived porous carbons with a high surface area and greatly improved supercapacitor performance," Small, vol. 13, Article ID 1602010, 2017.

[28] J. Wang, L. Shen, Y. Xu, H. Dou, and X. Zhang, "Lamellarstructured biomass-derived phosphorus- and nitrogen-codoped porous carbon for high-performance supercapacitors," New Journal of Chemistry, vol. 39, no. 12, pp. 9497-9503, 2015.

[29] C. Huang, A. M. Puziy, T. Sun et al., "Capacitive behaviours of phosphorus-rich carbons derived from lignocelluloses," Electrochimica Acta, vol. 137, pp. 219-227, 2014.

[30] J. M. Rosas, R. Ruiz-Rosas, J. Rodríguez-Mirasol, and T. Cordero, "Kinetic study of the oxidation resistance of phosphorus-containing activated carbons," Carbon, vol. 50, no. 4, pp. 1523-1537, 2012.

[31] X. Liu, W. Huang, D. Wang, J. Tian, and Z. Shan, "A nitrogendoped 3D hierarchical carbon/sulfur composite for advanced lithium sulfur batteries," Journal of Power Sources, vol. 355, pp. 211-218, 2017. 
[32] P. Kanninen, N. D. Luong, L. H. Sinh et al., "Highly active platinum nanoparticles supported by nitrogen/sulfur functionalized graphene composite for ethanol electro-oxidation," Electrochimica Acta, vol. 242, pp. 315-326, 2017.

[33] M. Chen, S. Jiang, C. Huang et al., "Honeycomb-like Nitrogen and Sulfur Dual-Doped Hierarchical Porous Biomass-Derived Carbon for Lithium-Sulfur Batteries," ChemSusChem, vol. 10, no. 8, pp. 1803-1812, 2017.

[34] X. Gu, Y. Wang, C. Lai et al., "Microporous bamboo biochar for lithium-sulfur batteries," Nano Research, vol. 8, no. 1, pp. 129139, 2014.

[35] M. R. Palacin, "Recent advances in rechargeable battery materials: a chemist's perspective," Chemical Society Reviews, vol. 38, pp. 2565-2575, 2009.

[36] Z. Zhu, S. Wang, J. Du et al., "Ultrasmall Sn nanoparticles embedded in nitrogen-doped porous carbon as highperformance anode for lithium-ion batteries," Nano Letters, vol. 14, no. 1, pp. 153-157, 2014.

[37] M. Kawaguchi, T. Kawashima, and J. Chem, "Synthesis of a new graphite-like layered material of composition $\mathrm{BC}_{3} \mathrm{~N}$," Journal of the Chemical Society, Chemical Communications, vol. 21, pp. 1133-1134, 1993.

[38] C. Shu, Y. Lin, B. Zhang, S. B. Abd Hamid, and D. Su, "Mesoporous boron-doped onion-like carbon as long-life oxygen electrode for sodium-oxygen batteries," Journal of Materials Chemistry A, vol. 4, no. 17, pp. 6610-6619, 2016.

[39] A. Kalijadis, J. Đorđević, T. Trtić-Petrović et al., "Preparation of boron-doped hydrothermal carbon from glucose for carbon paste electrode," Carbon, vol. 95, pp. 42-50, 2015.

[40] H. Guo and Q. Gao, "Boron and nitrogen co-doped porous carbon and its enhanced properties as supercapacitor," Journal of Power Sources, vol. 186, no. 2, pp. 551-556, 2009.

[41] K. C. Mondal, A. M. Strydom, Z. Tetana et al., "Boron-doped carbon microspheres," Materials Chemistry and Physics, vol. 114, no. 2-3, pp. 973-977, 2009.

[42] Z. Ling, G. Wang, M. Zhang et al., "Boric acid-mediated $\mathrm{B}, \mathrm{N}$-codoped chitosan-derived porous carbons with a high surface area and greatly improved supercapacitor performance," Nanoscale, vol. 7, no. 12, pp. 5120-5125, 2015.

[43] N. Shcherban, S. Filonenko, P. Yaremov, V. Dyadyun, I. Bezverkhyy, and V. Ilyin, "Boron-doped nanoporous carbons as promising materials for supercapacitors and hydrogen storage," Journal of Materials Science, vol. 52, no. 3, pp. 1523-1533, 2017.

[44] T. C. M. Chung, Y. Jeong, Q. Chen, A. Kleinhammes, and Y. $\mathrm{Wu}$, "Synthesis of microporous boron-substituted carbon $(\mathrm{B} / \mathrm{C})$ materials using polymeric precursors for hydrogen physisorption," Journal of the American Chemical Society, vol. 130, no. 21, pp. 6668-6669, 2008.

[45] K. C. Mondal, A. M. Strydom, R. M. Erasmus, J. M. Keartland, and N. J. Coville, "Physical properties of CVD borondoped multiwalled carbon nanotubes," Materials Chemistry and Physics, vol. 111, no. 2-3, pp. 386-390, 2008.

[46] J.-I. Ozaki, N. Kimura, T. Anahara, and A. Oya, "Preparation and oxygen reduction activity of BN-doped carbons," Carbon, vol. 45, no. 9, pp. 1847-1853, 2007.

[47] M. Kawaguchi, T. Kawashima, and J. Chem, "Synthesis of a new graphite-like layered material of composition $\mathrm{BC}_{3} \mathrm{~N}$," Journal of the Chemical Society, Chemical Communications, pp. 1133-1134, 1993.

[48] M. M. Titirici, A. Thomas, S.-H. Yu, J.-O. Müller, and M. Antonietti, "A direct synthesis of mesoporous carbons with bicontinuous pore morphology from crude plant material by hydrothermal carbonization," Chemistry of Materials, vol. 19, no. 17, pp. 4205-4212, 2007.

[49] T.-H. Mu, M. Zhang, L. Raad, H.-N. Sun, and C. Wang, "Effect of $\alpha$-Amylase Degradation on Physicochemical Properties of Pre-High Hydrostatic Pressure-Treated Potato Starch," Plos One, vol. 10, Article ID e0143620, 2015.

[50] M. Kaur, N. Singh, K. S. Sandhu, and H. S. Guraya, "Physicochemical, morphological, thermal and rheological properties of starches separated from kernels of some Indian mango cultivars (Mangifera indica L.)," Food Chemistry, vol. 85, no. 1, pp. 131140, 2004.

[51] T. Kyotani, T. Nagai, S. Inoue, and A. Tomita, "Formation of New Type of Porous Carbon by Carbonization in Zeolite Nanochannels," Chemistry of Materials, vol. 9, no. 2, pp. 609$615,1997$.

[52] S. F. Ahmed, S. Das, M. K. Mitra, and K. K. Chattopadhyay, "Molecular-level design of hierarchically porous carbons codoped with nitrogen and phosphorus capable of in situ selfactivation for sustainable energy systemstems," Indian Journal Pure Applied Physics, vol. 44, pp. 700-704, 2006.

[53] L. Nikiel and P. W. Jagodzinski, "Raman spectroscopic characterization of graphites: A re-evaluation of spectra/ structure correlation," Carbon, vol. 31, no. 8, pp. 1313-1317, 1993.

[54] A. C. Ferrari and J. Robertson, "Interpretation of Raman spectra of disordered and amorphous carbon," Physical Review B: Condensed Matter and Materials Physics, vol. 61, no. 20, pp. 14095-14107, 2000.

[55] M. J. Matthews, M. A. Pimenta, G. Dresselhaus, M. S. Dresselhaus, and M. Endo, "Origin of dispersive effects of the Raman D band in carbon materials," Physical Review B: Condensed Matter and Materials Physics, vol. 59, no. 10, pp. R6585-R6588, 1999.

[56] L. Bokobza, J.-L. Bruneel, and M. Couzi, "Raman spectroscopic investigation of carbon-based materials and their composites. Comparison between carbon nanotubes and carbon black," Chemical Physics Letters, vol. 590, pp. 153-159, 2013.

[57] R. N. Singh and R. Awasthi, "Low-macroscopic field emission from carbon fibers synthesized by direct current plasma enhanced chemical vapor deposition," Catalysis Science \& Technology Home, vol. 1, pp. 778-783, 2011.

[58] W. Qian, R. Hao, Y. Hou et al., "Solvothermal-assisted exfoliation process to produce graphene with high yield and high quality," Nano Research, vol. 2, no. 9, pp. 706-712, 2009.

[59] Y. Zhou, Q. Bao, L. A. L. Tang, Y. Zhong, and K. P. Loh, "Hydrothermal dehydration for the "green" reduction of exfoliated graphene oxide to graphene and demonstration of tunable optical limiting properties," Chemistry of Materials, vol. 21, no. 13, pp. 2950-2956, 2009.

[60] D. R. Rolison, "Catalytic nanoarchitectures-the importance of nothing and the unimportance of periodicity," Science, vol. 299, no. 5613, pp. 1698-1701, 2003.

[61] L. G. Bulusheva, A. V. Okotrub, A. G. Kurenya et al., "Electrochemical properties of nitrogen-doped carbon nanotube anode in Li-ion batteries," Carbon, vol. 49, no. 12, pp. 4013-4023, 2011.

[62] C. Kim, K. S. Yang, M. Kojima et al., "Fabrication of electrospinning-derived carbon nanofiber webs for the anode material of lithium-ion secondary batteries," Advanced Functional Materials, vol. 16, no. 18, pp. 2393-2397, 2006.

[63] S. B. Yang, X. L. Feng, L. J. Zhi, Q. A. Cao, J. Maier, and K. Müllen, "Nanographene-constructed hollow carbon spheres and their favorable electroactivity with respect to lithium storage," Advanced Materials, vol. 22, no. 7, pp. 838-845, 2010. 
[64] S. Goriparti, E. Miele, F. De Angelis, E. Di Fabrizio, R. P. Zaccaria, and C. Capiglia, "Review on recent progress of nanostructured anode materials for Li-ion batteries," Journal of Power Sources, vol. 257, pp. 421-443, 2014.

[65] J. Wu, X. Rui, G. Long, W. Chen, Q. Yan, and Q. Zhang, "Pushing Up Lithium Storage through Nanostructured Polyazaacene Analogues as Anode," Angewandte Chemie International Edition, vol. 54, no. 25, pp. 7354-7358, 2015.

[66] S. B. Yang, X. L. Feng, L. J. Zhi, Q. A. Cao, J. Maier, and K. Mullen, "Nanographene-constructed hollow carbon spheres and their favorable electroactivity with respect to lithium storage," Advanced Materials, vol. 22, pp. 838-842, 2010.

[67] F. Cheng, J. Liang, Z. Tao, and J. Chen, "Functional materials for rechargeable batteries," Advanced Materials, vol. 23, no. 15, pp. 1695-1715, 2011.

[68] J. Yi, X. P. Li, S. J. Hu et al., "Preparation of hierarchical porous carbon and its rate performance as anode of lithium ion battery," Journal of Power Sources, vol. 196, no. 16, pp. 6670-6675, 2011.

[69] N. A. Kaskhedikar and J. Maier, "Lithium storage in carbon nanostructures," Advanced Materials, vol. 21, no. 25-26, pp. 2664-2680, 2009.

[70] X. C. Liu, S. M. Li, J. Mei et al., "From melamine-resorcinolformaldehyde to nitrogen-doped carbon xerogels with microand meso-pores for lithium batteries," Journal of Materials Chemistry, pp. 14429-14438, 2014.

[71] M.-M. Titirici, R. J. White, N. Brun et al., "Sustainable carbon materials," Chemical Society Reviews, vol. 44, no. 1, pp. 250-290, 2015.

[72] B. B. Chang, Y. L. Wang, K. M. Pei, S. M. Yang, and X. P. Dong, " $\mathrm{ZnCl}_{2}$-activated porous carbon spheres with high surface area and superior mesoporous structure as an efficient supercapacitor electrode," RSC Advances, vol. 4, pp. 4054640552, 2014.

[73] H. J. Chen, H. M. Wei, N. Fu et al., "Nitrogen-doped porous carbon using $\mathrm{ZnCl}_{2}$ as activating agent for high-performance supercapacitor electrode materials," Journal of Materials Science, vol. 53, pp. 2669-2684, 2018.

[74] G. Ma, Q. Yang, K. Sun et al., "Nitrogen-doped porous carbon derived from biomass waste for high-performance supercapacitor," Bioresource Technology, vol. 197, pp. 137-142, 2015. 


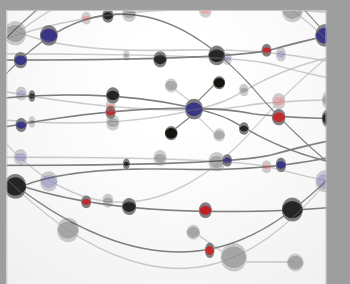

The Scientific World Journal
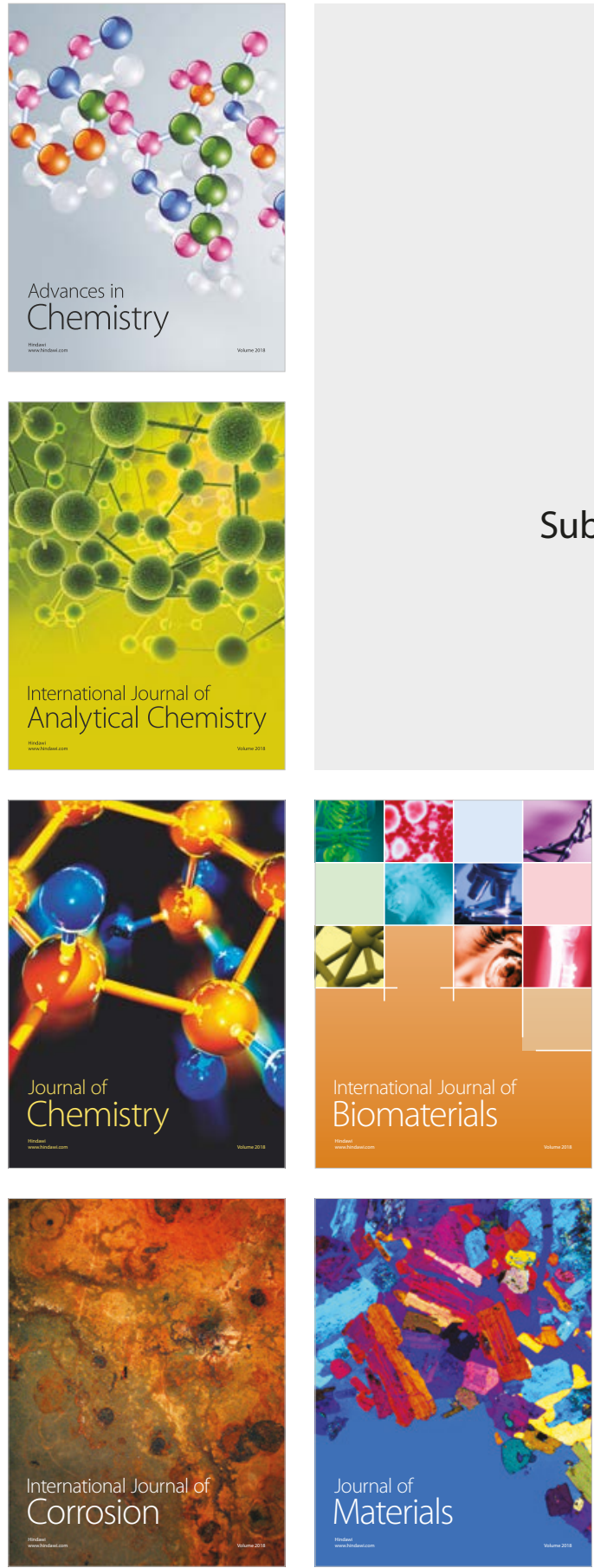

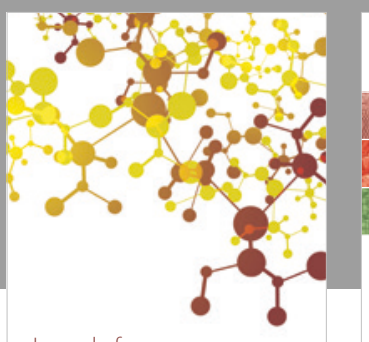

Journal of

Applied Chemistry
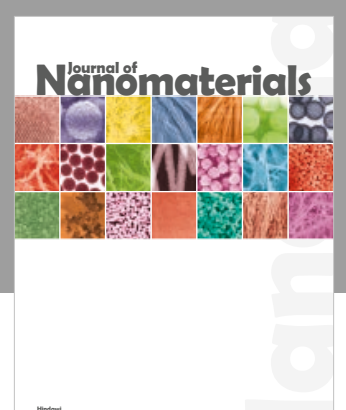

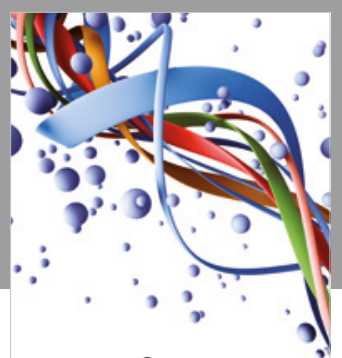

Scientifica

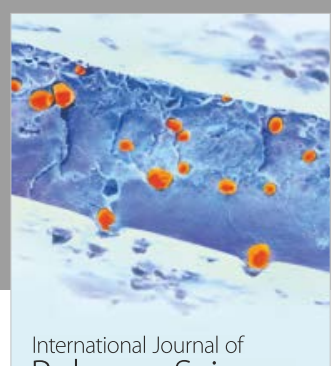

Polymer Science

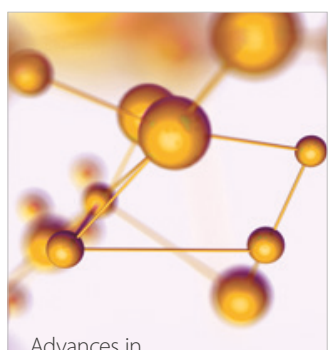

Physical Chemistry
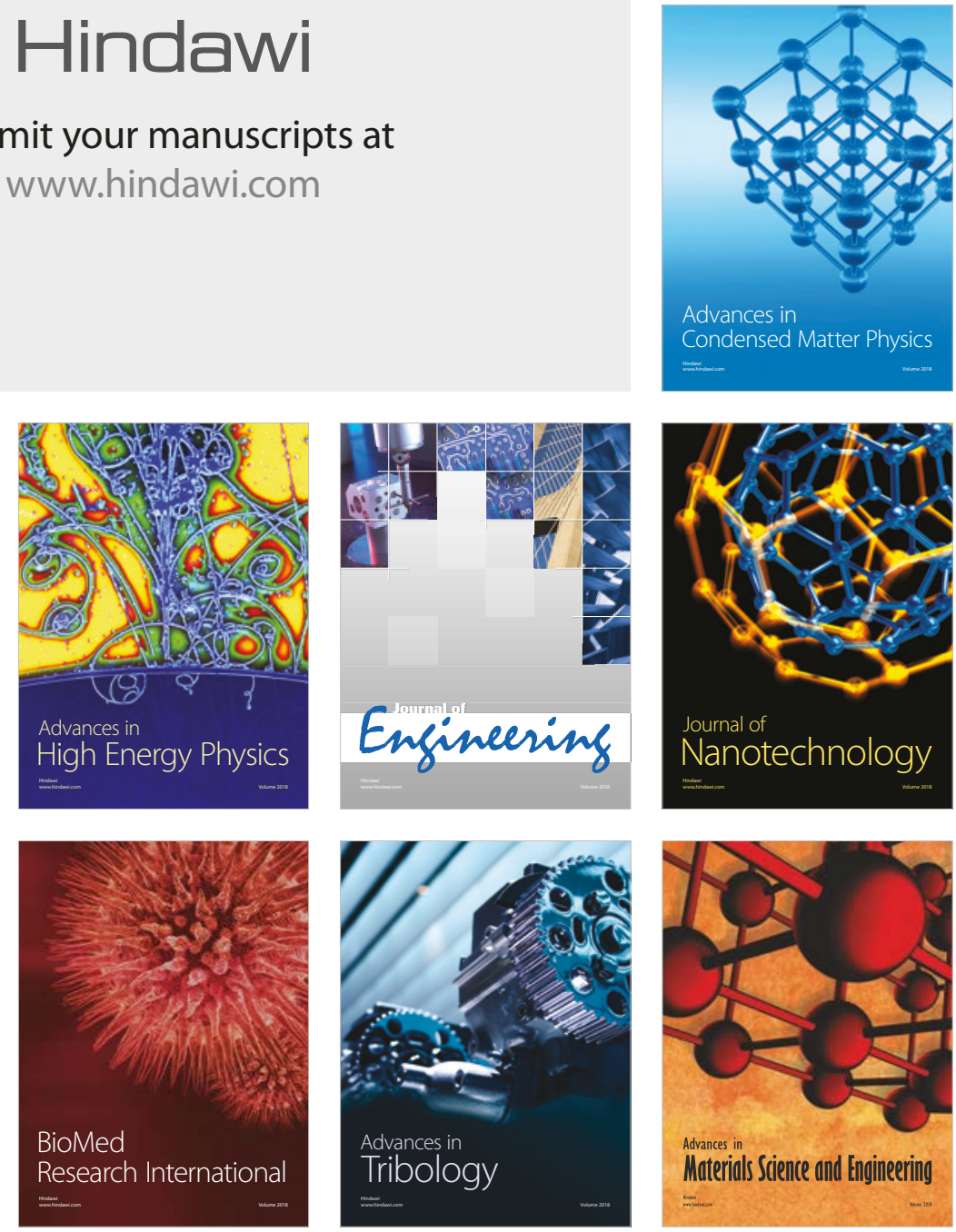